\title{
Cellular polypeptides overexpressed after herpes simplex infection permit virus subtyping and may help diagnose cervical cancer
}

\author{
J M DAVIS, * N B LA THANGUE, $\ddagger$ D L TAYLOR, * D S LATCHMAN, $\dagger$ \\ M ANDERSON,§ A S TYMS*
}

From the *Division of Virology, Department of Medical Microbiology, St Mary's Hospital Medical School, the $\dagger$ Department of Zoology, University College, the $\ddagger$ National Institute for Medical Research, and the §Samaritan Hospital, London

SUMMARY The synthesis of cellular macromolecules is inhibited after infection with herpes simplex viruses (HSV) although certain host proteins accumulate to high concentrations as identified by monoclonal antibody TG7A. By western blotting, a polypeptide with a relative molecular weight of 90 kilodaltons was identified in cells infected with type 2 viruses and a polypeptide of 40 kilodaltons relative molecular weight in type 1 infected cells, and virus typing was confirmed by restriction enzyme analysis of viral DNA. Thirty seven clinical isolates from the genital region were subtyped as HSV type 2 and 18 from the orofacial region as type 1 by the different intracellular location of the 90 kilodalton and 40 kilodalton proteins seen on immunofluorescent staining of cells infected with HSV. Expression of these proteins has been associated with cellular transformation due to gene products of HSV or other viruses. Overexpression of the cellular proteins identified by TG7A reactivity was shown to be a marker for cells in cervical smears from patients with CIN III that appeared to be dyskaryotic. Little or no reaction was observed in squamous epithelial cells found in normal or abnormal smears.

Herpes simplex viruses (HSV) have been classified into type 1 or type 2 strains by variation in structure of polypeptide ${ }^{1}$ or genome ${ }^{23}$ and by antigenic differences. ${ }^{4}$ Type 1 viruses are generally associated with the orofacial region, and type 2 viruses with the urogenital tract, ${ }^{5}$ although this is not a strict rule, ${ }^{6}$ and their location probably reflects the epidemiology rather than any precise tissue tropism. Subgenomic DNA fragments or defective virus particles of both type 1 and type 2 viruses are capable of transforming cells in culture, ${ }^{7}$ and such cells are tumorigenic in vivo. ${ }^{8}$ Similarly, HSV has been shown to act as a tumour initiator in at least one animal model of carcinogenesis. ${ }^{9}$ This information coupled with epidemiological evidence, ${ }^{10}{ }^{11}$ indicates a possible role for HSV in the aetiology of cervical cancer. It may act as an initiating agent, rendering cells susceptible to transformation with human papillomaviruses types 16 and 18 that, although found in a high proportion of women with

Address for reprints: Dr A S Tyms, MRC Collaborative Centre, 1-3 Burtonhole Lane, Mill Hill, London NW7 IAD

Accepted for publication 4 April 1988 cervical tumours, ${ }^{12-14}$ are also found in women without detectable cervical abnormality. ${ }^{1516}$

During lytic infection with HSV, cellular macromolecular synthesis is strongly repressed, although several cellular proteins accumulate to high concentrations during infections with prototype viruses. ${ }^{17}$ A monoclonal antibody, TG7A, raised against extracts of cells infected with HSV, recognises two such proteins. One has a relative molecular weight of 90 kilodaltons, which is related to a 90 kilodalton heat shock protein, and accumulates in cells infected with HSV type 2; the other protein has a relative molecular weight of 40 kilodaltons and accumulates in. type 1 infected cells. ${ }^{18}$ These proteins are also overexpressed in cells transformed by HSV, by other DNA or RNA viruses, or in immortalised cells, ${ }^{19}$ and they may therefore have a role in maintaining the transformed phenotype.

We report here two further observations on the polypeptide defined with TG7A. Firstly, HSV recently isolated from patients caused the cellular proteins to be overexpressed during lytic infection, which permitted the identification of the viruses as being of type 1 or 
type 2. Secondly, during investigations of cervical smears from patients with moderate to severe dyskaryosis and CIN III proved by biopsy, we identified abnormal cells that showed strong immunofluorescence with monoclonal antibody TG7A. The cells failed to react with monoclonal antibody specific for HSV encoded protein. This suggests that the overexpression of the cellular proteins may provide a marker of transformation in situ, thus permitting the identification of dysplastic cells.

\section{Methods}

HER PES SIMPLEX VIRUSES AND CER VICAL SMEARS Prototype viruses used were HSV type 2 strains 333 and HG52 and HSV type 1 strain 171. Low passage clinical isolates of $\mathrm{HSV}$ (TA, JV, and 3M) were obtained from patients at St Mary's Hospital attending the STD clinic or from the department of routine diagnostic virology. Clinical isolates were initially grown in human embryonic fibroblasts (HEF). Abnormal cervical smears were obtained from the Samaritan Hospital, and control smears from a family planning clinic.

\section{POLYPEPTIDE ANALYSIS AND WESTERN BLOTTING}

Baby hamster kidney cells (BHK 21) were grown in 25 $\mathrm{cm}^{2}$ plastic tissue culture flasks and infected at a multiplicity of infection of at least one plaque forming unit (pfu)/cell. After being incubated for 24 hours, cells were harvested and disrupted in sample buffer. Polypeptides were separated under reducing conditions by discontinuous sodium dodecyl sulphatepolyacrylamide gel electrophoresis (SDS-PAGE), with molecular weight standards, in a $12.5 \%$ running gel cross linked with $\mathbf{N}, \mathbf{N}^{\prime}$ diallytartardiamide. Proteins were transferred electrophoretically to nitrocellulose (Amersham International), reacted with monoclonal antibody TG7A, and then reacted with peroxidase labelled antimouse conjugate. The methods used were similar to those described previously. ${ }^{17}$

\section{RESTRICTION ENZYME ANALYSIS}

HEF cells infected with virus as indicated above, were exposed to $15 \mu \mathrm{Ci} / \mathrm{ml}$ radiophosphorus $\left({ }^{32} \mathrm{P}\right)$ orthophosphate, and the total DNA was extracted after incubation for 24 or $\mathbf{4 8}$ hours. Viral DNA fragments were resolved on autoradiographs after being digested with restriction enzymes and separated on agarose gels, as described elsewhere. ${ }^{20}$

\section{IMMUNOFLUORESCENCE AND CYTOLOGICAL PROCEDURES}

HEF cells grown on $13 \mathrm{~mm}$ glass coverslips were exposed to virus to provide populations of infected cells. After being fixed in acetone, cell monolayers were subjected to indirect immunofluorescence using TG7A or control monoclonal antibodies directed against HSV type specific or cytomegalovirus (CMV) specific proteins. This was followed by immunofluorescence with an antimouse fluorescein isothiocyanate conjugate using $1 \%$ Evan's blue as a counterstain. Cervical smears were provided on multiplace teflon coated slides, which were stained as described above. Preparations were viewed and photographed using a Leitz epifluorescent microscope system.

\section{Results}

MOLECULAR DEFINITION OF CLINICAL ISOLATES OF HSV

A woman aged 19 attended the STD clinic at St Mary's

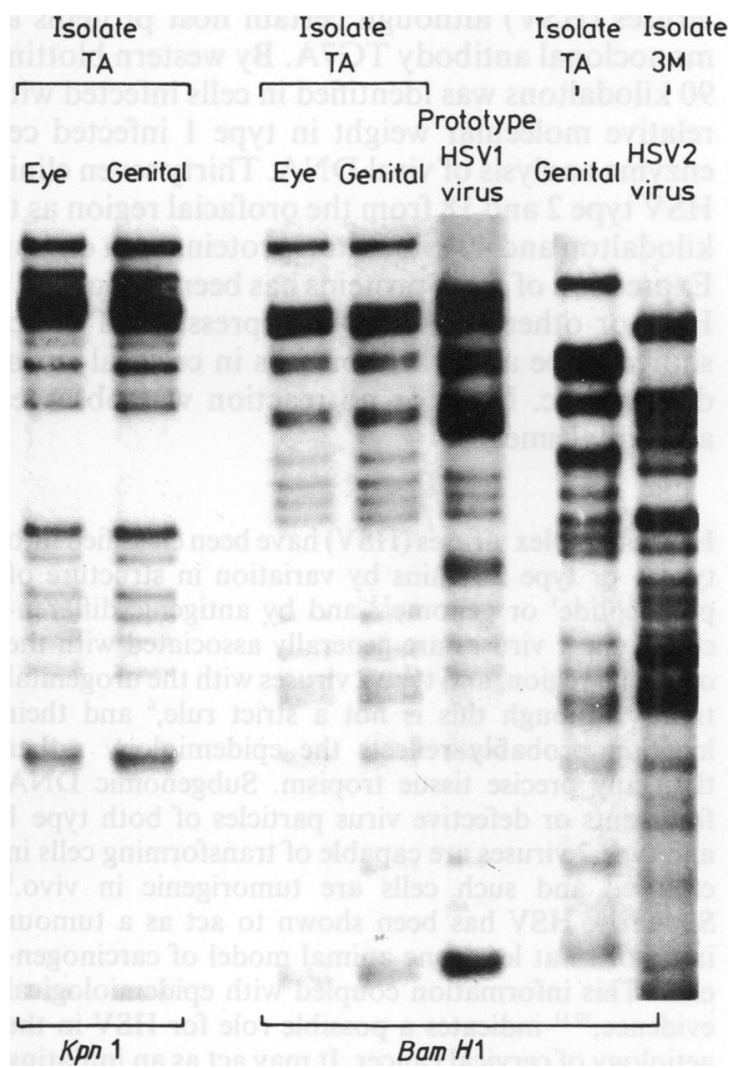

Fig 1 Characterisation of $H S V$ isolates by restriction enzyme analysis of viral DNA after labelling with radiophosphorus $\left({ }^{32} P\right)$ orthophosphate. Genital and facial isolates (isolate TA) from one patient were identified as $\mathrm{HSV}$ type 1 by comparing restriction profiles with a prototype HSV 1 strain. All type 1 viruses were clearly distinguishable from type 2 genital isolate $3 M$ by absence of comigrating DNA fragments. 


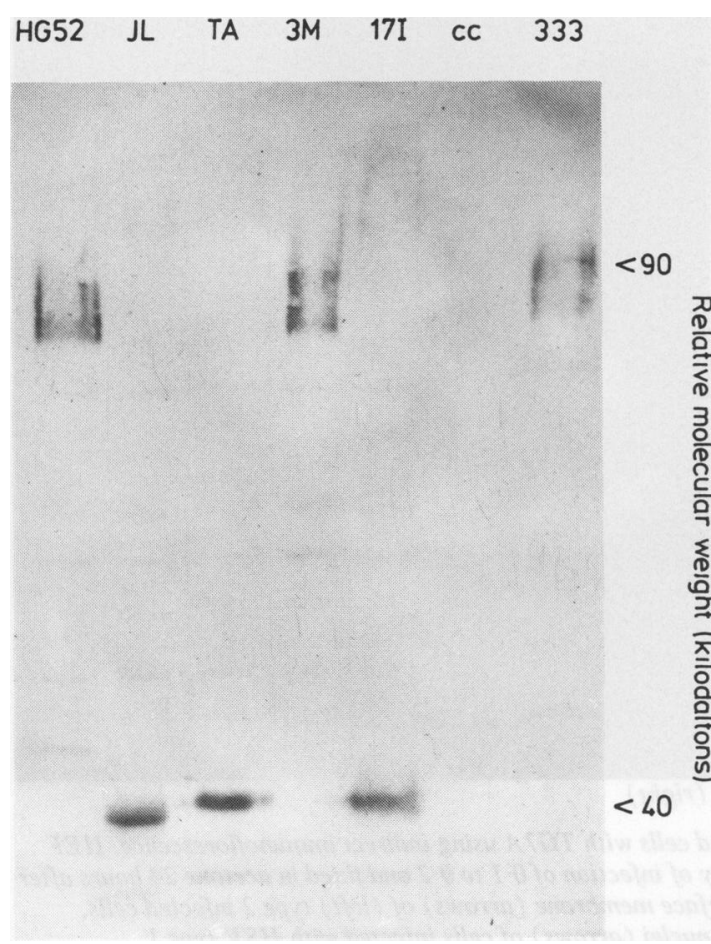

Fig 2 Western blot blind analysis of proteins extracted from cells infected with HSV type 1 or 2 using monoclonal antibody TG7A. BHK 21 cells infected with HSV type 1 strains (JL, TA, or 17I) or type 2 strains (HG52, 333, or $3 M$ ) at a multiplicity of infections of 1 or more plaque forming units (pfu)/cell or left uninfected (control cells (cc)) were harvested 24 or 48 hours after infection. Overexpressed cellular proteins with molecular weights of 90 kilodaltons (type 2) and 40 kilodaltons (type 1) were resolved by immunoblotting with TG7A.

Hospital with symptoms of genital herpes with no previous history of infection. Four days later, she complained of vesicular eruptions on the right eyelid. Viruses isolated from both sites were unequivocally identified as HSV type 1 by restriction enzyme analysis of viral DNA, and were indistinguishable by analysis with Kpn 1 and Bam H1 (fig 1) or Eco R1 and Xho 1 (results not shown). This showed that a single virus (isolate TA) had caused simultaneous infection at two distinct anatomical sites. Virus isolated from the patient's vulva was grown for 24 hours in BHK 21 cells, and polypeptides were separated by SDS-PAGE and analysed by western blotting using monoclonal antibody TG7A. In the $\mathbf{4 0}$ kilodalton relative molecular weight region we detected an abundant polypeptide (fig 2), which was absent from uninfected cells. Similar results were recorded with a type 1 clinical isolate (isolate JL) from a second patient, prototype type 1 virus 17 I (fig 2), and three other clinical isolates including virus TA isolated from the patient's eyelid (results not shown).

A man with a history of recurrent genital herpes periodically attended the STD clinic at St Mary's Hospital. Virus (isolate $3 \mathrm{M}$ ) isolated from lesions on his penis was identified as HSV type 2 by restriction enzyme analysis of viral DNA (fig 1). Western blot analysis detected a cellular protein with a molecular weight of 90 kilodaltons when BHK21 cells were infected with the $3 \mathrm{M}$ strain or prototype type 2 strains 333 and HG52 (fig 2). Similar results were recorded with four other clinical isolates of HSV type 2 (results not shown).

\section{SUBTYPING WITH MONOCLONAL ANTIBODY TG7A} USING IMMUNOFLUORESCENCE

The intracellular location of cellular proteins overexpressed after HSV infection varies between serotypes. In studies with prototype viruses, the lower relative molecular weight protein associated with HSV type 1 infected cells was intracellular, predominantly in the nucleus, whereas the higher relative molecular weight protein of type 2 infections was restricted to the cytoplasm and surface membrane. We subtyped 37 clinical isolates from patients with recurrent genital herpes and 18 isolates from orofacial lesions, on the basis of the staining reaction with monoclonal antibody TG7A using indirect immunofluorescence. Specimens were coded and classified blind as HSV type 1 or type 2 by this method (fig 3 ). The identify of the various isolates confirmed the previous identification by restriction enzyme analysis of viral DNA or by type specific monoclonal antibodies to virus encoded proteins.

\section{INVESTIGATION OF CYTOLOGICAL SMEARS WITH} MONOCLONAL ANTIBODY TG7A

Four patients with moderate to severe dyskaryosis had atypical transformation zones identified at colposcopy; all four had acetowhite epithelium and two also had areas of congenital transformation zone. Microscopy of specimens obtained at colposcopically directed biopsies showed CIN III in all four patients (see table). Three women attending a family planning clinic provided the control samples. Monoclonal antibody against HSV type 2 encoded proteins was included on each slide to identify specifically any cells expressing viral antigen.

In cervical smears from the four patients with abnormal cytology, cells apparently dyskaryotic in appearance showed strong immunofluorescence in the cytoplasm after reaction with TG7A (fig 4), but no reactive cells were seen when stained with the monoclonal antibodies specific for HSV or CMV. The negative reaction of monoclonal antibodies specific 


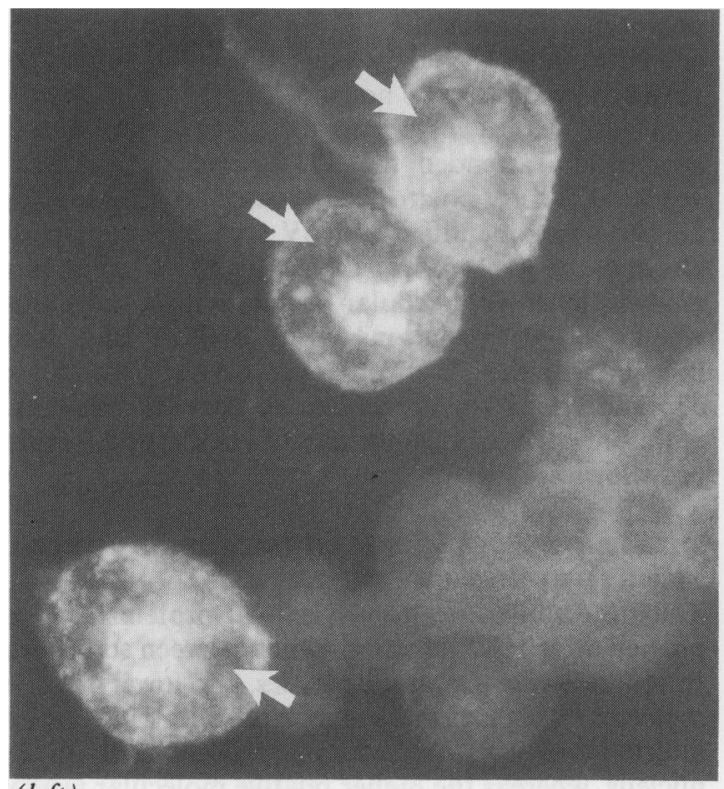

(left)

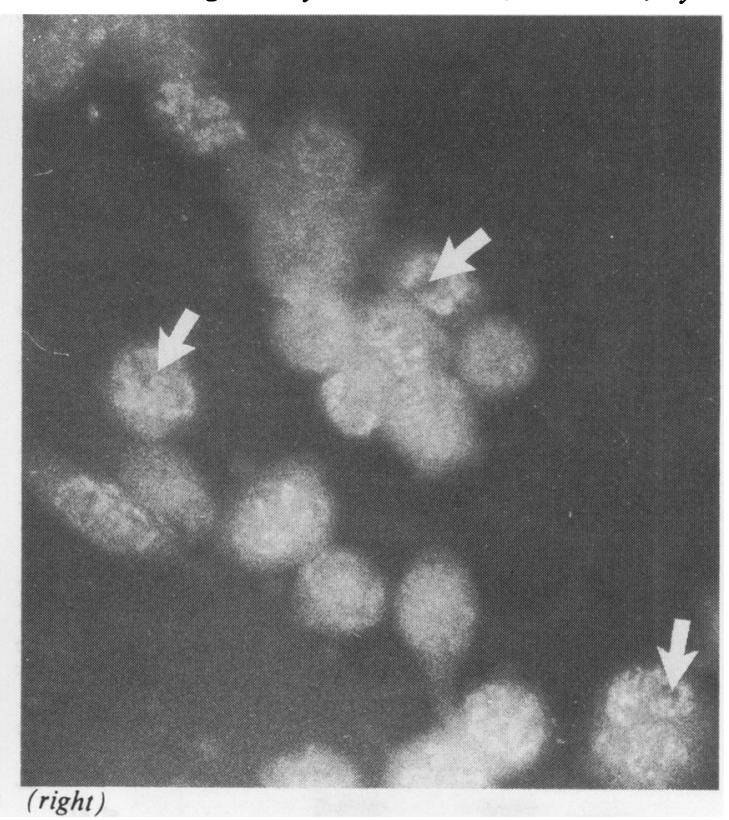

Fig 3 Blind identification of HSV type 1 and HSV type 2 infected cells with TG7A using indirect immunoflorescence. HEF cells were infected with HSV type 1 or type 2 virus at a multiplicity of infection of 0.1 to 0.2 and fixed in acetone 24 hours after infection. Immunofluorescence was restricted to cytoplasm and surface membrane (arrows) of (left) type 2 infected cells, shown here as polynucleated cells and (right) generally located in nuclei (arrows) of cells infected with HSV type 1 .

for these viruses excluded the possibility of false reactions with TG7A because of non-specific binding of monoclonal antibody. Most squamous cells in the smears containing abnormal cells stained negatively, as indicated by the red fluorescence due to the counterstain. A few cells were weakly positive with TG7A. Three smears from the control group contained cells that were negative for all three monoclonals (fig 4), although one smear showed an occasional cell reactive with TG7A.

\section{Discussion}

Although the association of papillomavirus infection with human cervical cancer is well documented,${ }^{1314}$ the observation that this virus is also present in a proportion of women without cervical abnormality ${ }^{116}$ suggests that other factors may operate. These may act as initiating agents that render cells vulnerable to subsequent transformation with papillomavirus. ${ }^{12} \mathrm{HSV}$ represents an obvious candidate for such an initiating agent, as defective virus can transform cells in vitro ${ }^{7}$ and in vivo and HSV DNA sequences have been found in about $10 \%$ of malignant genital tumours. ${ }^{21}$ Several cellular proteins clearly accumulate during lytic infection with HSV, and these same proteins are known to be overexpressed in transformed cells. ${ }^{19}$ Thus HSV may activate the synthesis of cellular polypeptides that may contribute to the transformed phenotype, forming a basis for the "hit and run" model. Such a change in the pattern of cellular gene expression has recently been suggested as the basis of initiating events in cervical carcinogenesis, whether activated by HSV or other agents. ${ }^{22}$

The results presented here showed that the overexpression of cellular proteins was also a characteristic

Table Details of patients with abnormal cervical smears

\begin{tabular}{lllll}
\hline Case No & Age & Dyskaryosis & Colposcopic findings & Histology \\
\hline 1 & 28 & Severe & Atypical transformation zone (ATZ) and acetowhite epithelium (AWE) & CIN III \\
2 & 28 & Moderate & ATZ, also congenital transformation zone (CTZ), and AWE with punctation & CIN III \\
3 & 30 & Severe & ATZ, CTZ, and AWE & CIN III \\
4 & 35 & Severe & ATZ and AWE & CIN III \\
\hline
\end{tabular}



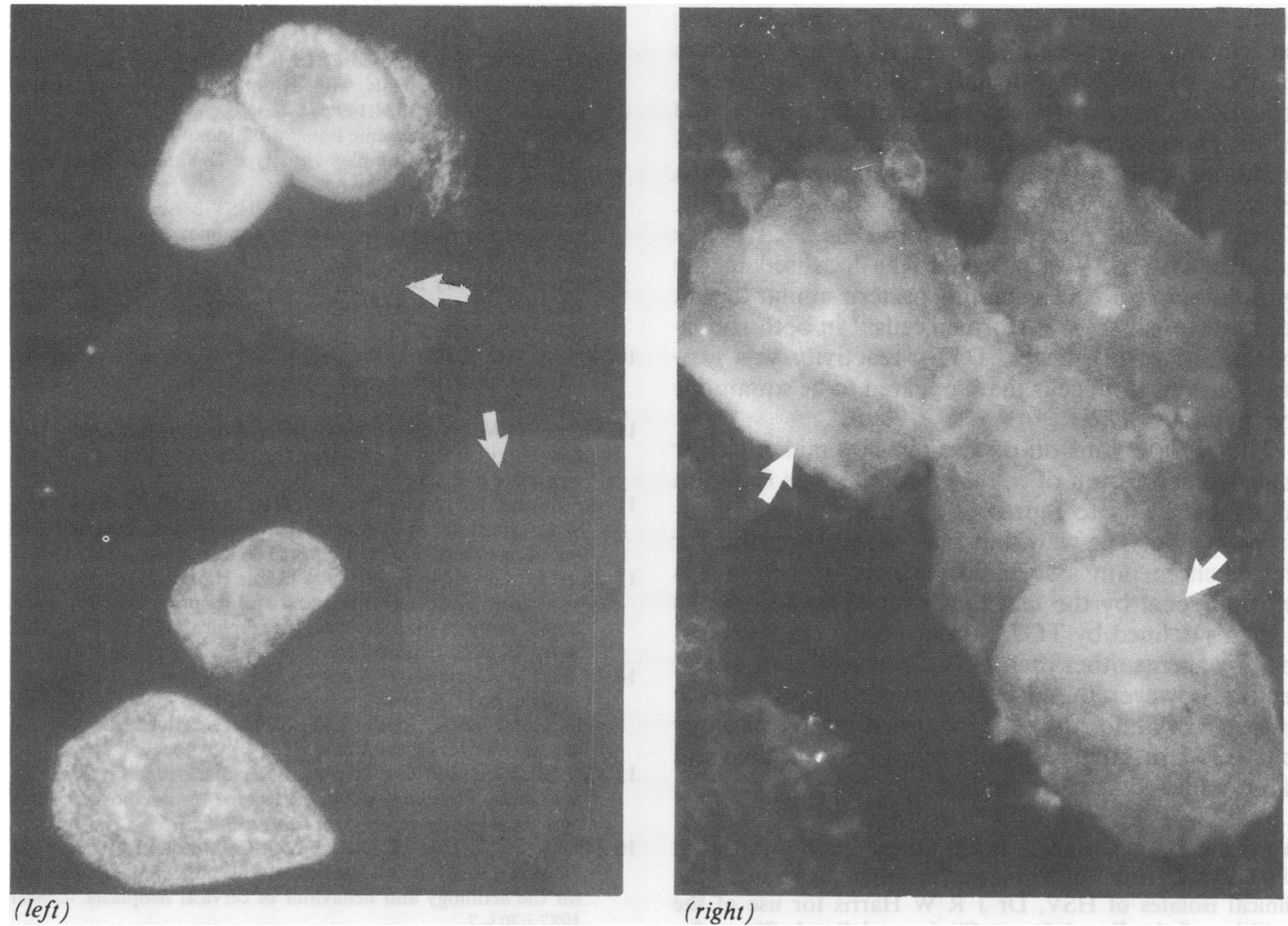

Fig 4 Cells in cervical smears from women with CIN III or women attending family planning clinic. Each smear was reacted with TG7 A monoclonal antibody, HSV type 2 specific monoclonal antibody, CMV specific monoclonal antibody, or phosphate buffered saline. Smears from patients with CIN III (left) contained cells that were dyskaryotic in appearance and showed intense reaction with TG7A, but not with either of the virus specific monoclonal antibodies. Squamous cells (arrows) were devoid of the reaction in these abnormal smears. Smears from women attending family planning clinic (right) contained squamous cells (arrows) that in general showed little or no reaction with any of the monoclonal antibodies used.

of clinical isolates of HSV, and not a phenomenon strictly related to laboratory adapted prototype viruses. In fact, western blot analysis of the 40 kilodalton and 90 kilodalton polypeptides clearly differentiated between HSV type 1 and type 2 infection, and immunocytological analysis by monoclonal antibody TG7A provided a new and accurate means of subtyping HSV using a single reagent. This could provide an advantage in diagnostic applications.

Although HSV type 2 is the serotype most closely linked with cervical cancer, the increased incidence of HSV type 1 in the genital region shows that this virus type may also play a part. HSV type 1 infection has been recorded in about $20 \%$ of first episode attacks of genital herpes, ${ }^{6}$ although it was apparently not associated with recurrent episodes at that anatomical site. In our investigation of primary type 1 infection, both the genital and facial isolates from one patient induced the expression of the lower relative molecular weight polypeptide and provided evidence that the accumulation of specific cellular proteins was serotype specific and not associated with a site related tropism. Primary infection with HSV type 1 in the genital region in the presence of recurrent type 2 infection is not uncommon, and this situation is made more complex by the high incidence of symptomless infections with HSV. ${ }^{23}$ This may indicate a role for dual infection with the different serotypes in the transformation process in vivo.

Our previous work has suggested that the overexpression of both the $\mathbf{4 0}$ kilodalton and $\mathbf{9 0}$ kilodalton relative molecular weight proteins was a general marker for the transformed phenotype, and was not restricted to HSV induced changes during lytic infection. ${ }^{19}$ The main antigenic component of the transformed cell appeared to be the 90 kilodalton poly- 
peptide, as deduced from immunoprecipitating experiments using sera from rats bearing tumours induced by HSV transformed cells. In the present report, we have provided evidence that abnormal cervical smears from patients diagnosed for CIN III contained cells, dyskaryotic in appearance, which reacted strongly with monoclonal antibody TG7A. The immunofluorescent reaction in cells not lytically infected with HSV appeared to be localised in the cytoplasmic region in a staining pattern similar to that seen previously for transformed cells. ${ }^{19}$ In both abnormal and control smears, TG7A reactivity was generally absent from cells that appeared to be squamous morphologically.

The observations on cervical smears make it clear that overexpression of cellular proteins was found in cells most likely to represent the transformed phenotype in vivo. The view that HSV was responsible for this phenomenon associated with transformation is left equivocal by the fact that overexpression of the proteins defined by TG7A occurred in cells transformed by agents other than HSV. Irrespective of causal factors, however, the correspondence seen between the presence of abnormal cells identified by morphology and TG7A reactivity could be of prognostic value and is the subject of further studies.

We thank Dr A F Hanna, Praed Street Clinic, and Dr Jill Underhill, Division of Virology, for providing some of the clinical isolates of HSV, Dr J R W Harris for use of the facilities of the Praed Street Clinic, and Sarah Sharp for preparing the manuscript.

\section{References}

1 Lonsdale DM, Brown SM, Subak-Sharpe JH, Warren KG, Koprowski $M$. The polypeptide and the DNA restriction enzyme profiles of spontaneous isolates of herpes simplex virus type 1 from explants of human trigeminal, superior cervical and vagus ganglia. J Gen Virol 1979;43:151-71.

2 Chaney SMJ, Warren KG, Kettyls J, Zbitnue A, Subak-Sharpe JH. A comparative analysis of restriction enzyme digests of the DNA of herpes simplex virus isolated from genital and facial lesions. J Gen Virol 1983;64:357-71.

3 Buchman TG, Simpson T, Nosal C, Roizman B, Nahmias AJ. The structure of herpes simplex virus DNA and its application to molecular immunology. Ann NY Acad Sci 1980;354:279-90.

4 Plummer G, Goodheart CR, Miyogi M, Skinner GRB, Thouless ME, Wildy P. Herpes simplex viruses: discrimination of types and correlation between different characteristics. Virology 1974;60:206-16.

5 Dundarov S, Andorov P, Bakalov B. Characteristics of herpes simplex virus variants isolated from patients with various diseases. Arch Virol 1980;63:115-21.

6 Schmidt OW, Fife KH, Corey LJ. Reinfection is an uncommon occurrence in patients with symptomatic recurrent genital herpes. Infect Dis 1984;149:645-6.

7 Duff R, Rapp F. Oncogenic transformation of hamster cells after exposure to herpes simplex virus type 2. Nature; New Biology 1971;233:48-50.

8 Macnab JCM. Tumour production by HSV-2 transformed lines in rats and the varying response to immunosuppression. $J$ Gen Virol 1979;43:39-56.

9 Burns JC, Murray BK. Conversion of herpetic lesions to malignancy by ultra-violet exposure and promoter application. J Gen Virol 1981;55:305-13.

10 Minson AC. Cell transformation and oncogenesis by herpes simplex virus and human cytomegalovirus. Cancer Surveys 1984;3:91-111.

11 Macnab JCM. Herpes simplex virus and human cytomegalovirus: their role in morphological transformation and genital cancer. $J$ Gen Virol 1987;68:2525-50.

12 zur Hausen H. Human genital cancer: synergism between two virus infections or synergism between a virus infection and initiating events? Lancet 1982;ii:1370-2.

13 Durst M, Gissmann L, Ikenbery H, zur Hausen H. A papilloma virus from a cervical carcinoma and its prevalence in cancer biopsy samples from different geographical regions. Proc Natl Acad Sci USA 1983;80:3812-3.

14 Bushart M, Gissmann L, Idenberg H, Kleinheinz A, Schewlen W, zur Hausen H. A new type of papilloma virus DNA, its presence in genital cancer biopsies and in cell lines derived from cervical cancer. EMBO J 1984;3:1151-7.

15 Cox EF, Meanwell CA, Maitland NJ, Blackledge G, Scully C, Jordan JA. Human papillomavirus type 16-homologous DNA in normal human ectocervix. Lancet 1986;ii:157-8.

16 Meanwell CA, Cox MF, Blackledge G, Maitland NJ. HPV 16 DNA in normal and malignant cervical epithelium: implications for the aetiology and behaviour of cervical neoplasia. Lancet 1987;i:703-7.

17 La Thangue NB, Shriver K, Davison C, Chan WL. Herpes simplex virus infection causes the accumulation of a heat shock protein. EMBO J 1984;3:267-77.

18 La Thangue NB, Latchman DS. A cellular protein related to heat shock protein 90 accumulates during herpes simplex virus infection and is over expressed in transformed cells. Exp Cell Res 1988;178:169-79.

19 Macnab JCM, Orr A, La Thangue NB. Cellular proteins expressed in herpes simplex virus transformed cells also accumulate on herpes virus infections. EMBO J 1985;4:3223-8.

20 Davis JM, Jeffries DJ, Walker D, Tyms AS. Molecular biology in viral diagnosis: restriction enzyme analysis of viruses from recurrent genital herpes infections. Analyst 1985;110:605-9.

21 Park M, Kitchener HC, Macnab JCM. Detection of herpes simplex virus type-2 DNA restriction fragments in human cervical carcinoma tissue. EMBO J 1983;2:1029-34.

22 zur Hausen $\mathbf{H}$. Intra-cellular surveillance of persisting viral infections. Lancet 1986;ii:489-91.

23 Mertz GJ, Schmidt O, Jourden JL, et al. Frequency of acquisition of first-episode genital infection with herpes simplex virus from symptomatic and asymptomatic source contacts. Sex Transm Dis 1985;12:33-9. 